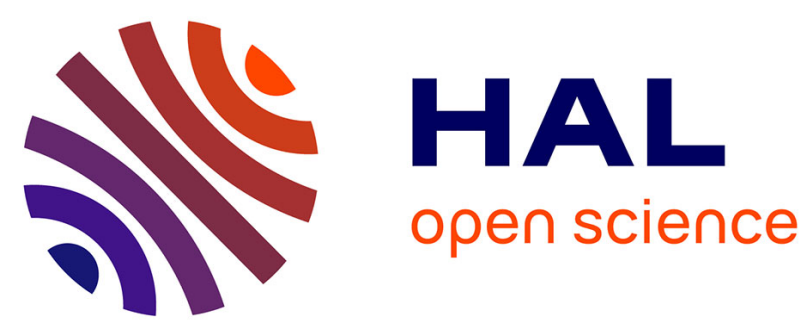

\title{
Experimental Analysis of the Shot Peening Particle Stream Using Particle Tracking and Digital Image Correlation Techniques
}

\author{
R.F. Kubler, R. Rotinat, J. Badreddine, Q. Puydt
}

\section{To cite this version:}

R.F. Kubler, R. Rotinat, J. Badreddine, Q. Puydt. Experimental Analysis of the Shot Peening Particle Stream Using Particle Tracking and Digital Image Correlation Techniques. Experimental Mechanics, 2020, pp.1-15. 10.1007/s11340-019-00574-4 . hal-02465775

\section{HAL Id: hal-02465775 \\ https://hal.science/hal-02465775}

Submitted on 15 Sep 2020

HAL is a multi-disciplinary open access archive for the deposit and dissemination of scientific research documents, whether they are published or not. The documents may come from teaching and research institutions in France or abroad, or from public or private research centers.
L'archive ouverte pluridisciplinaire HAL, est destinée au dépôt et à la diffusion de documents scientifiques de niveau recherche, publiés ou non, émanant des établissements d'enseignement et de recherche français ou étrangers, des laboratoires publics ou privés. 


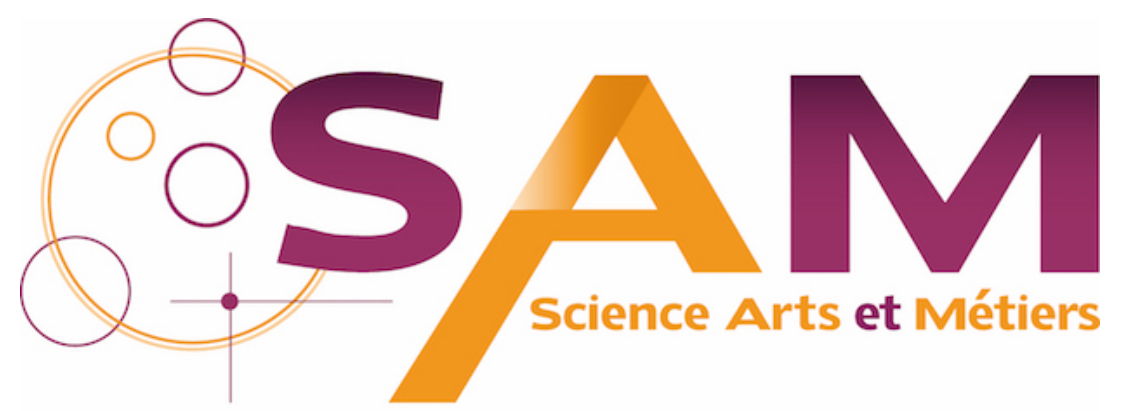

Archive Ouverte - Open Repository

\section{Science Arts \& Métiers (SAM)}

is an open access repository that collects the work of Arts et Métiers ParisTech researchers and makes it freely available over the web where possible.

This is an author-deposited version published in: https://sam.ensam.eu Handle ID: .http://hdl.handle.net/10985/18005

\section{To cite this version :}

R.F. KUBLER, R. ROTINAT, J. BADREDDINE, Q. PUYDT - Experimental Analysis of the Shot Peening Particle Stream Using Particle Tracking and Digital Image Correlation Techniques Experimental Mechanics p.1-15 - 2020 


\title{
Experimental Analysis of the Shot Peening Particle Stream Using Particle Tracking and Digital Image Correlation Techniques
}

\author{
R.F. Kubler ${ }^{1}$ (i) $\cdot$ R. Rotinat ${ }^{2} \cdot$ J. Badreddine ${ }^{3} \cdot$ Q. Puydt ${ }^{4,5}$
}

\begin{abstract}
The conventional air pressure shot peening process consists of multiple impacts of particles propelled with pressurized air through a nozzle at the surface of mechanical components. An experimental study of the flow of particles exiting the nozzle was conducted. A high speed camera was used for image acquisition of the particle flow. This particle flow was analyzed using a particle tracking (PT) technique and using a digital image correlation (DIC) technique. Those two methods were compared and applied to the characterization of an industrial shot peening flow with several parameters of jet pressure and mass flow rate.
\end{abstract}

Keywords Shot peening flow $\cdot$ Velocimetry $\cdot$ Particle tracking $\cdot$ Digital image correlation

\section{Introduction}

Shots of particles are present in the study of many processes (particle injection, spray combustion, particle laden flows, blasting and conventional shot peening) at many scales. The interest of the analysis of particle flow lies in the control of the particle kinematics and the ability to predict the particle density and the shape of the stream. This study aims to analyse the particle flow ahead of a shot peening nozzle where steel beads (i.e. particles) are projected on a mechanical surface. Developing experimental methods to characterize a particle flow is useful to obtain the contact conditions (location, velocity vector) of any interesting geometry submitted to a shot peening flow.

R.F. Kubler

regis.kubler@ensam.eu

1 Arts et Metiers Institute of Technology, MSMP, HESAM Université, 2 cours des Arts et Metiers, Aix-en-Provence, 13617, France

2 Arts et Metiers Institute of Technology, MSMP, HESAM Université, rue Sainte-Dominique, Chalons-en-Champagne, 51006, France

3 Safran Tech, Rue des Jeunes Bois, Chateaufort, Magny-Les-Hameaux, 78772, France

4 IRT M2P, 4 rue Augustin Fresnel, Metz, 57070, France

5 Present address: ArcelorMittal, Florange, 57190, France
In jet flow engineering [1], the jet ahead of the nozzle is described by a turbulent behavior. Figure 1 shows the structure of the turbulent jet [2]. A potential core region is formed near the nozzle exit. In this region, the velocity is usually assumed to be constant. This potential core region is surrounded by a mixing region until the jet becomes fully developed forming the developed region. Shakouchi [1] expresses the size of the core region as 5.d independently of the air pressure, where $d$ is the diameter of the nozzle.

Tsuji et al. [3] carried out measurements in an axisymmetric jet laden with coarse particles (170 $1400 \mu \mathrm{m}$ ) to measure air velocimetry, particle velocity and concentration using a Laser Doppler Velocimeter (LDP), a Pitot tube and a fiber probe. They showed that the particle velocity is smaller than the air velocity at the exit of the nozzle. At a distance from the nozzle exit, particles accelerate and their velocities become greater than the air velocity. They observed that the velocity of the particles is at its highest in the centerline of the stream.

Green et al. [4] used electrodynamic electrodes mounted on an extension $90 \mathrm{~mm}$ from the nozzle and monitored the signal to control the mean velocity of the particles. Capacitive [5] and electrostatic [6, 7] sensors were frequently used to measure online the continuous velocity of particles in pneumatic pipelines. In application to a shotpeening blast, [8] used two methods to measure particle velocity: a mechanical measuring device based on a rotating disc principle, an electronic particle velocity measurement system with two microphone-based impact sensors. The 


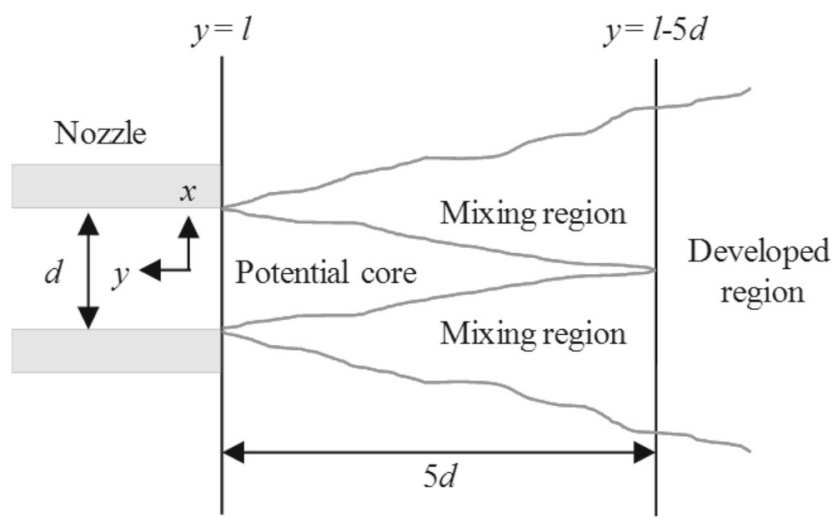

Fig. 1 Description of the structure of a turbulent jet ahead of a nozzle [2]

authors [9] later improved the electronic system and the resulting signal by using three microphones with an increased damping of the vibrations.

Non intrusive methods such as particle image velocimetry (PIV) are whole field methods giving an instantaneous field of flow. It is often used in fluid dynamics and in powder projection. Laser Doppler Velocimetry (LDV) is based on the Doppler shift using light detection [10]. This technology has been used for shot peening flow [11]. A distribution of particle velocities can be obtained at a given position away from the nozzle. The Doppler method is traversing the flow domain.

Santo et al. [12] studied the velocity of particles in a pneumatic conveyer using a high speed camera and a mirror to obtain 3D data. Aiba et al. [13] used a high speed camera to measure the average velocity at 3 specific distances ahead of the nozzle for different particle diameters and jet pressures. They concluded that as the particle size decreases or the jet pressure increases, the particle velocity increases.

Fluid dynamics investigations have been carried out to analyse the importance of Stokes numbers on the velocity and concentration distribution of a multiphase flow [14, 15]. The authors showed that the flow outside of the nozzle is characterised by a process of particle reorganisation, resulting in significant particle migration towards the jet axis or away from the centreline respectively for low values of Stokes number and for high values of Stokes number.

Object tracking [16], which is an important task in the global field of computer vision is a suitable tool to be used for particle tracking. In the presented study, ponctual objects are treated. Objects detected in consecutive frames are represented by points and the association of the points is based on the previous object state which can include object position and motion. Tracking acts as the correspondence of detected objects represented by points across frames. Point correspondence is a complicated problem, especially in the presence of misdetections, entries and exits of particles, which would be the case of a shot peening flow. 3D trajectories can also be estimated from 2D motions [17].
In fluid mechanics, stereo-imaging is generally adopted for measurements of profiles and velocity. A particle image velocimetry (PIV) technique is often used in the fluid mechanics community. PIV is used to measure the velocity of the fluid. Particle tracking velocimetry (PTV) is used to track particles that are resident within a fluid and measure their velocity. Close to the presented study, PTV has been used to analyse the velocities of particles in the cold spray process with a transparent nozzle [18]. Particles velocities from a multiphase flow were supersonic at their maximum and their probability distribution function followed a Gaussian fit.

Digital Image Correlation (DIC) is widely adopted by the solid mechanics community and applied to measure displacement fields [19-21]. With less information than PTV, DIC can be a simple tool for characterizing the global motion of particles. Passieux et al. [22] used the DIC technique to measure the rigid body motion of an impactor. A pattern is sprayed on a spherical projectile to track its rigid body motion in terms of translations and rotations. Optical flow technics tracking the movement of brightness patterns can also be used to track particles [23].

DIC has been used to measure velocities of gas bubbles in water [24]. A 3D DIC method has been applied to measure the displacement at the surface of a sloshing liquid [25]. Chatellier et al. [26] have combined DIC and PIV methods in the field of fluid mechanics. Zhao et al. [27] studied particle flow in a fluid by implementing stereobased particle tracking in a friction extrusion process.

Kato et al. [2] modeled the particle flow exiting a nozzle using motion of particle equations [28], considering the air velocity in each region that was creating a drag force and the transverse force acting on particles leading to a divergent jet.

In the case of shot peening, the interactions between the stream of shots and a mechanical part result in a coverage rate and a transferred energy to the material generating residual mechanical fields in the subsurface of the material. Badreddine et al. [29] developed a kinematical numerical model to predict the interaction of shots with parts of complex geometry in the case of ultrasonic shot peening. They obtained a map of the coverage on the part and of the resulting velocity. Nguyen et al. [30] used multiphase computational fluid dynamics to predict the coverage as a function of the process parameters. They used ANSYSFluent to compute the trajectories of the particles in a multiphase air flow charged with particles.

The presented work aimed at characterizing the velocity of particles ahead of a shot peening nozzle for different process parameters with two different techniques: particle tracking (PT) velocimetry and digital image correlation (DIC). From the images acquired using a high speed camera, those techniques enabled to obtain 2D projections of the velocity contours and density contours. The 
Fig. 2 Experimental set up. a Lightning set up ahead of the nozzle. b High speed camera outside of the machine. c Identification of zones ahead of the nozzle

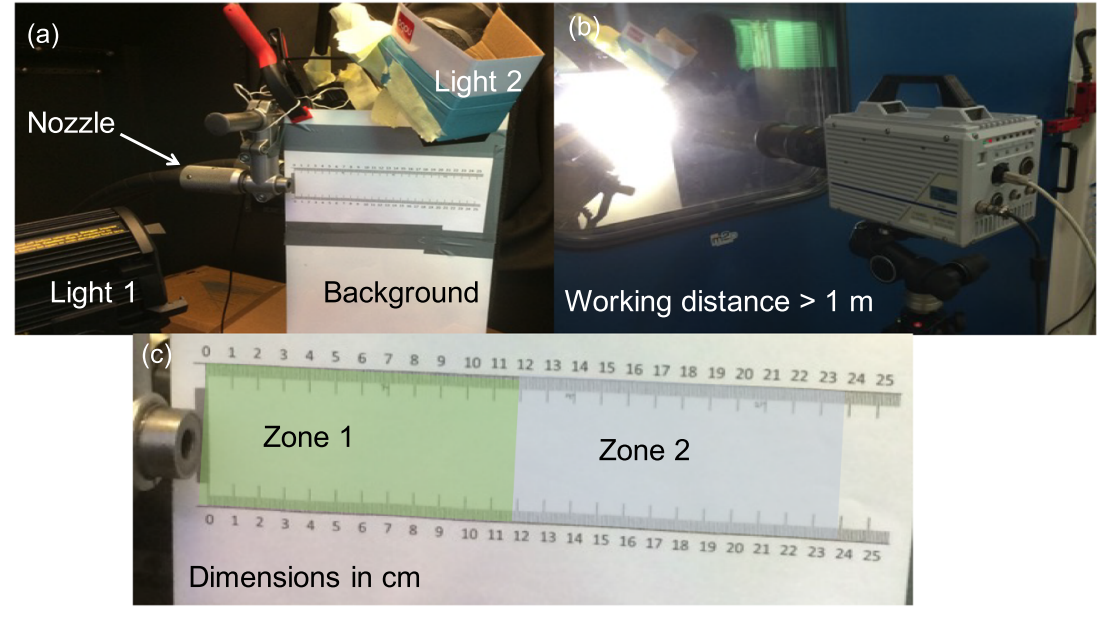

experimental set-up is presented in Section "Experimental Set Up". Section "Analysis Using Particle Tracking (PT) Velocimetry" is dedicated to the presentation of the particle tracking method and to the analysis of the results in terms of velocity distribution in the stream ahead of the nozzle. Section "Analysis Using Digital Image Correlation (DIC)" presents the DIC method applied to the measurement of the velocity in the stream using the same acquired images. The results from the two techniques were compared and discussed. A phenomenological model for predicting the average stable particle velocity as a function of the process parameters is proposed in this section.

\section{Experimental Set Up}

The shot peening machine used was a Wheelabrator Sisson Lehmann installed at IRT M2P. Conventional peening with a straight nozzle was studied in this work. Figure 2 shows the experimental set-up used for the high speed video acquisitions. The lighting of the scene was set inside the peening chamber with a Decool projector positioned behind the nozzle and a LED projector at the top of the particle flow (Fig. 2(a)). A high speed Photron SA5 camera was positioned outside the peening cabine in front of the window using a $28-105 \mathrm{~mm}$ lens at a working distance of approximatively $1 \mathrm{~m}$. A white background was set behind the blast parallel to the nozzle direction. A scale was affixed to this background to calibrate the measurements. Images with a size of $896 \times 704 \mathrm{~mm}$ were taken with frame rate of 12000 images per second and an aperture time of 1/69000 $s$. An average of 4000 images were taken per acquisition.

A single straight nozzle with a $10 \mathrm{~mm}$ diameter was used with S230 steel shots with an average diameter of $584 \mu \mathrm{m}$. Two zones of interest were observed in the blast ahead of the nozzle. Zone 1 and zone 2 were respectively between 0 and $120 \mathrm{~mm}$ ahead of the horizontal nozzle and between
120 and $240 \mathrm{~mm}$. The field depth was adjusted to obtain a good focus on particles close to the centerline of the stream. Direction $\mathrm{X}$ was along the flow direction and direction $\mathrm{Y}$ was the transverse perpendicular direction in the plane of observation.

The tested parameters were the jet pressure $P$ in bars, the mass flow rate $D$ of shots in $\mathrm{kg} / \mathrm{min}$. The pressure was measured by a manometer placed in the pneumatic system before the nozzle. The mass flow rate was measured by a scale located after the shot selectors. For the parametric study, the jet pressure is set at 1, 3 and 5 bars and mass flow rate at 3,6, 9 and $13 \mathrm{~kg} / \mathrm{min}$. Figure 3 shows the investigated parameters in the different zones. Additional sets of parameters were analyzed in zone 2 compared to zone 1 . In order to assess the effect of the process parameters $D$ and $P$, some results will be presented in the same chart as proposed in Fig 3.

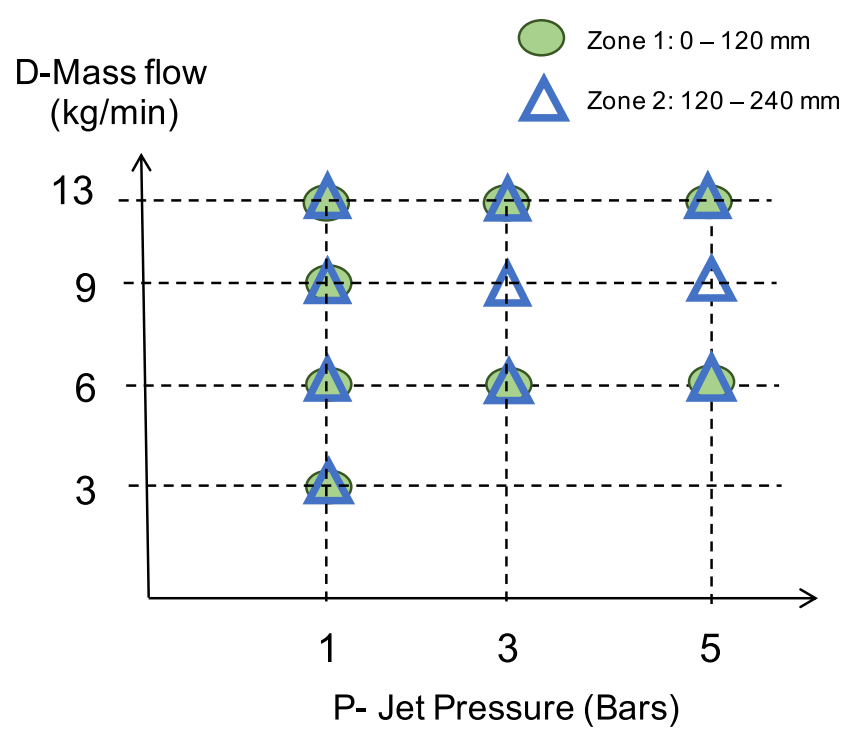

Fig. 3 Process parameters investigated in the different observed zones 
Fig. 4 Observation of the flow ahead of the nozzle, in a zone 1 $(0-120 \mathrm{~mm})$ and in b zone 2 (120-240 mm), for different process parameters

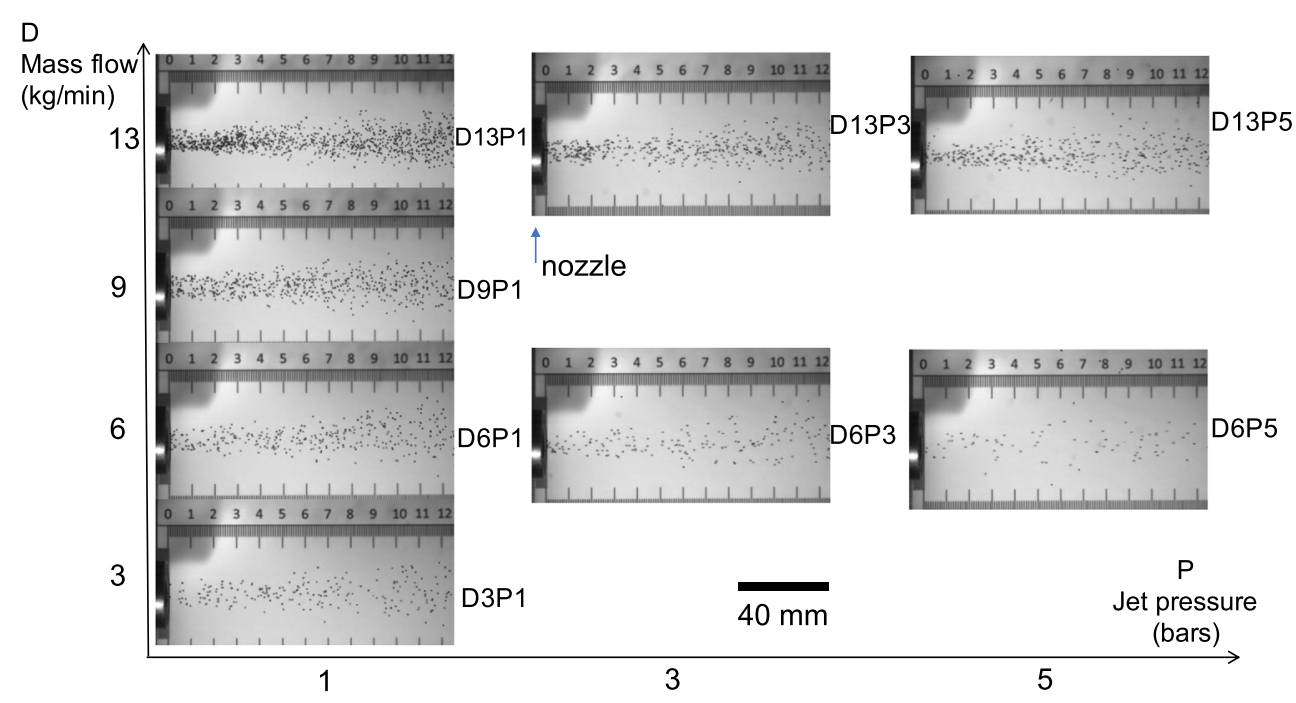

(a)

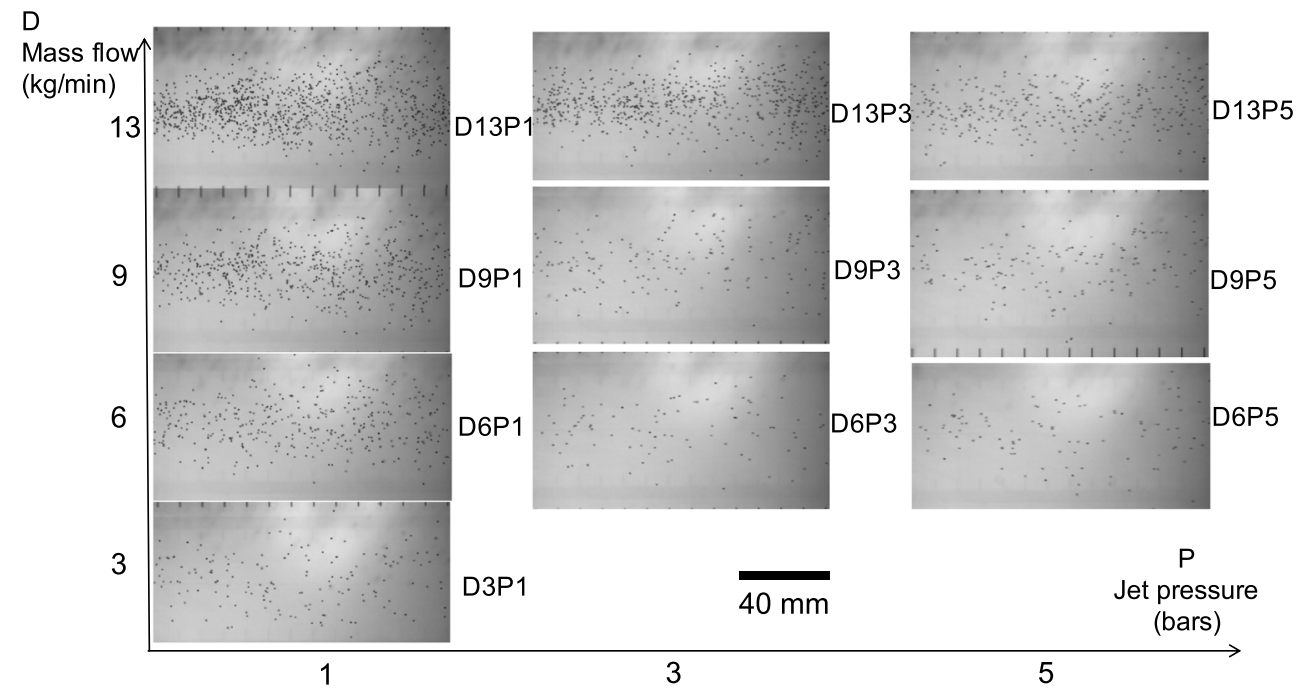

(b)
A series of images was obtained for each selected process parameter allowing representative measurements of the kinematics of different particles at several positions in the flow. Figure 4 shows some representative observations of the flow for the different process parameters $(D, P)$ respectively in zone 1 and in zone 2 . From a qualitative point of view, it was observed that the higher the mass flow rate, the more dense the flow was. Moreover, for a given mass flow rate, a higher pressure will distance the particles from each other.

\section{Analysis Using Particle Tracking (PT) Velocimetry}

This section presents the particle tracking velocimetry (PTV) technique and the analysis of the acquired images.
The velocity contours projected in direction $X$ and $Y$ were investigated. More focus was brought on the component $V_{X}$ of the velocity. The evolution of $V_{X}$ was measured as a function of the distance to the nozzle. A particle count was also performed.

\section{Particle Tracking Technique}

Particle tracking velocimetry (PTV) was carried out on the obtained 2D images using TrackMate module [31] available in FIJI software [32]. TrackMate module performs single particle tracking and follows the different detected spots by extracting the $\mathrm{X}, \mathrm{Y}$ coordinates over time and rebuilds the trajectory of the particles as presented in Fig. 5. Preprocessing of the raw images (Fig. 5(a)) was performed before using TrackMate and images with white spots over a black background are used (Fig. 5(b)). The trajectories over 
Fig. 5 PT in the flow. a Raw image, $\mathbf{b}$ Pre-processing of the image, $\mathbf{c}$ Obtained trajectories over 400 images after filtering

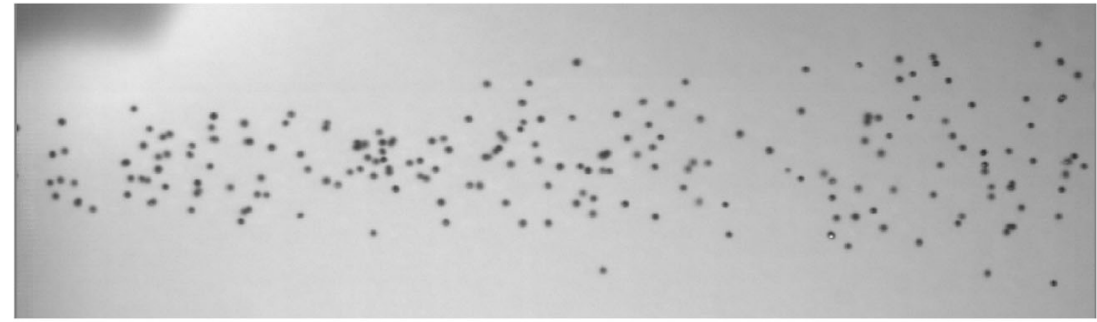

(a)

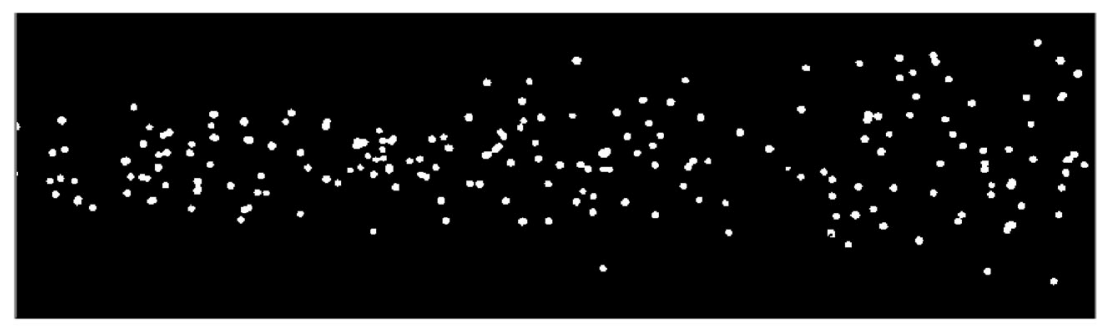

(b)

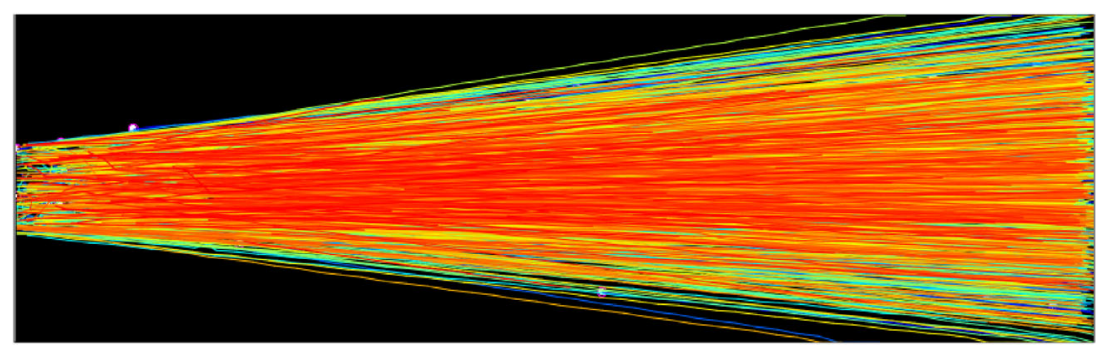

(c)
400 images were detected by particle linking and filtered in order to eliminate spurious paths after superimposition of two particles that were not in the same plane (Fig. 5(c)). Two consecutive images were compared in order to obtain the velocities in direction $X$ and direction $Y$ projected in the 2D plane of view. The calculated value of velocity was plotted at the position of the particle in the first image. The evolution of the velocities along the trajectory was obtained as a contour map.

Since TrackMate detects the position of the particles, a particle count was carried out. All the post-processings and the contour mappings were performed with Matlab. The data were plotted over a surface of area $h_{x} \times h_{y}=2 \times 2 \mathrm{~mm}^{2}$.

\section{Results: Velocity Fields in Zone 1 and 2}

Figures 6 and 7 present the average velocity $V_{X}$ contours of the particles detected at each position $\left(h_{x} \times h_{y}=2 \times 2 \mathrm{~mm}^{2}\right)$ in zone 1 and zone 2 respectively. In Fig. 6, the position of the nozzle at $X=0$ can be observed. In Fig. 7, position $X=0$ in zone 2 corresponds to position $X=60$ in zone 1 . Extrapolating to $3 \mathrm{D}$, the jet seemed to adopt a conical shape. The velocity of the shots was minimal at the exit of the nozzle and the shots accelerated ahead of the nozzle. This stream corresponded to the turbulent jet observed in fluid mechanics ahead of a nozzle. A potential core where the velocity is constant was observed at the exit of the nozzle. The size of the potential core was bigger as the jet pressure $P$ increased. The potential core was bounded by two mixing layers between the jet and the quiescient medium, where the particles accelerated. Beyond a critical distance $x_{0}$, a fully established flow occurred.

The obtained data were post-treated in order to plot the average velocity of particles as a function of the distance to the nozzle as sketched in Fig. 8. A mean value of velocity at a position $X$ was obtained by excluding zero values. The standard deviation is also plot in Fig. 8. The standard deviation represents the deviation of the velocity from the mean value at a distance $X$ from the nozzle head. It can be observed that the deviation from the mean velocity is larger at higher pressures and closer to the nozzle where the jet is still turbulent. This deviation gives rise to noise on the mean velocity curve that is explained by turbulent areas close to the nozzle. Moreover for higher pressure, more interactions between shots may affect the average value of velocity. Those particle tracks where interactions occured were mainly taken out of the analysis by the automatic filtering procedure, but some of them still remained as 


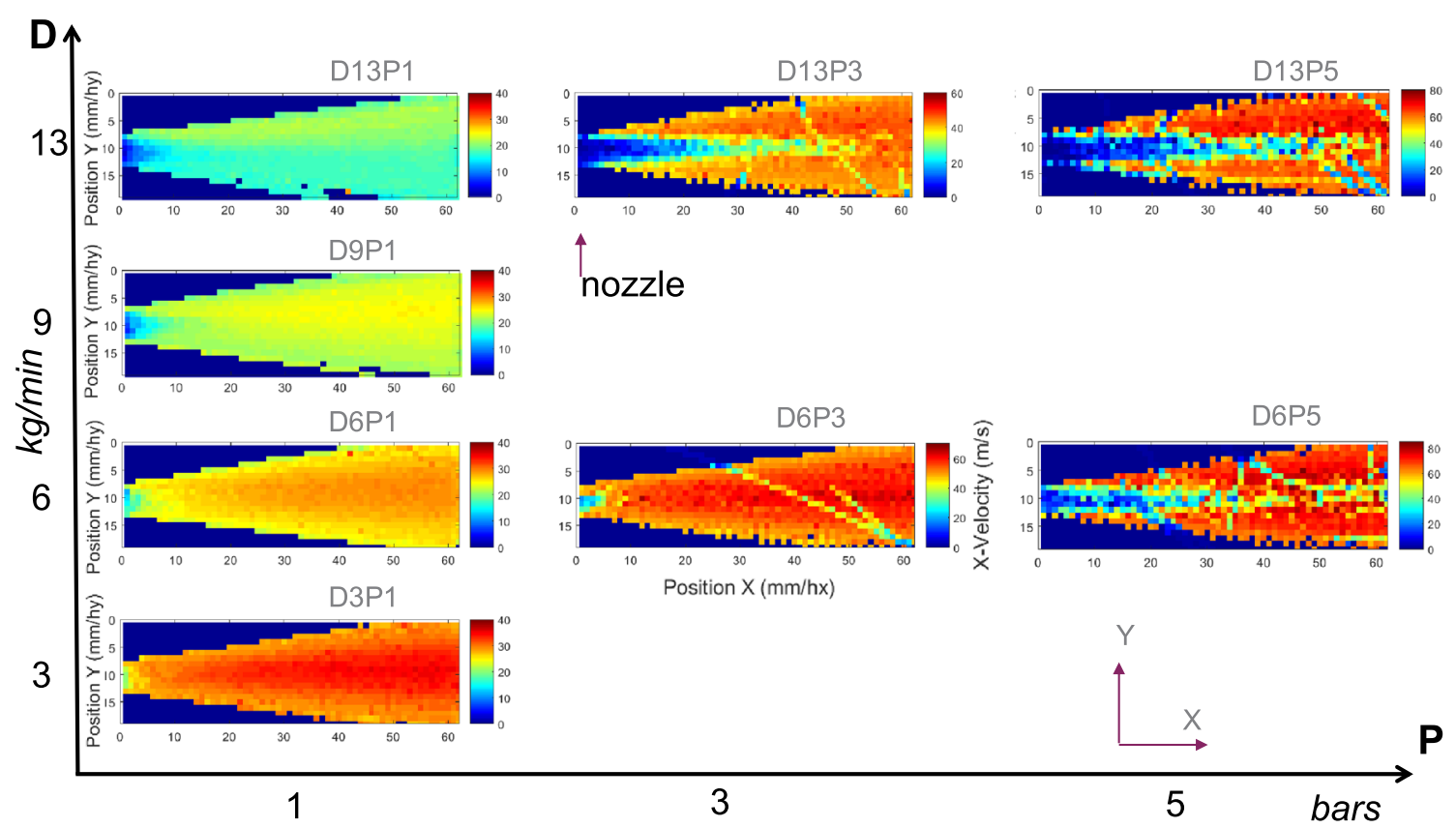

Fig. 6 Particle tracking: $V_{X}$ velocity contours in the flow ahead of the nozzle in zone 1 for different process parameters. Average over a surface $\mathrm{S}$ of $4 \mathrm{~mm}^{2}, h_{x}=h_{y}=2 \mathrm{~mm}$

observed for D6P3. For a mass flow rate of $13 \mathrm{~kg} / \mathrm{min}$, Fig. 8 shows that particles accelerated at the nozzle exit. Figures 9(a) and (b) show the mean velocity $V_{X}$ along direction $X$ for the different process parameters $(D, P)$ respectively in zone 1 and zone 2 . It was observed that for a pressure of 1 bar the mean velocity reached a maximum and was stable after a position $X=20$. This location corresponded to the end of the potential core as previously observed in Fig. 6. The length of the potential core increased with the mass flow rate $D$. For the same pressure (1 bar), the mass flow rate $D$ had also an effect on the mean velocity. The denser the flow was, the lower the average velocity.

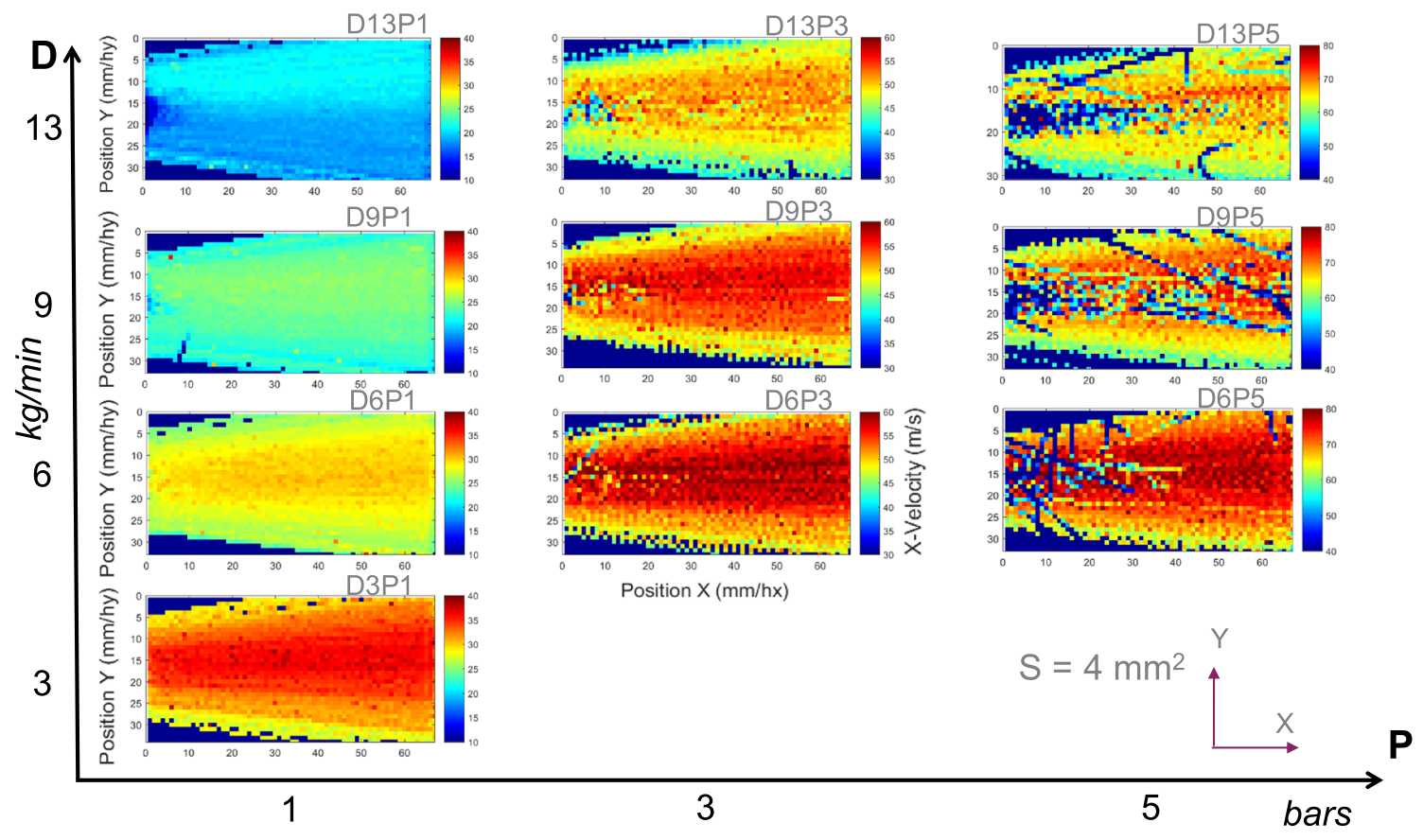

Fig. 7 Particle tracking: $V_{X}$ velocity contours in the flow ahead of the nozzle in zone 2 for different process parameters. Average over a surface $\mathrm{S}$ of $4 \mathrm{~mm}^{2}, h_{x}=h_{y}=2 \mathrm{~mm}$. Position $X=0$ in zone 2 corresponds to position $X=60$ in zone 1 

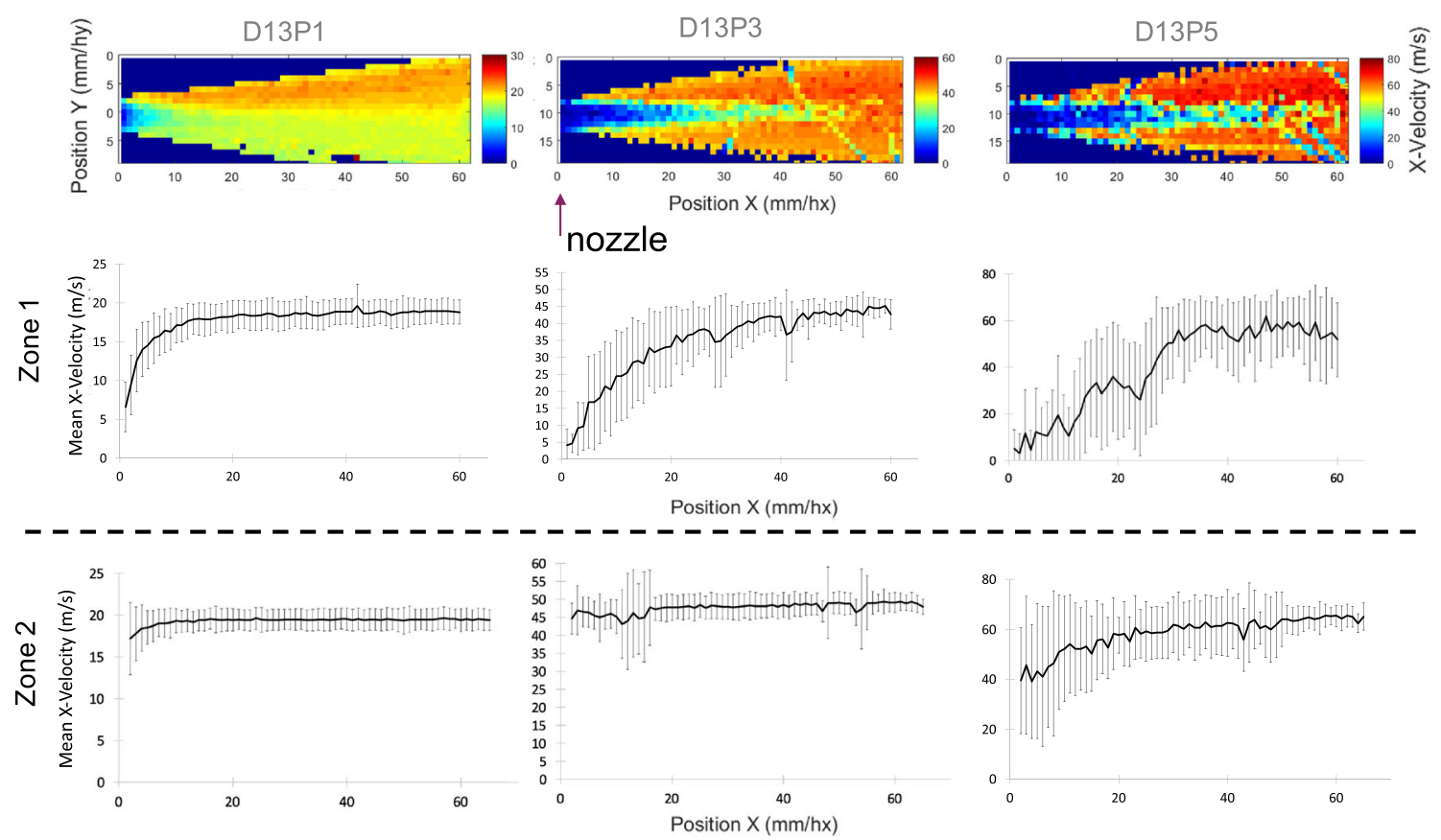

Fig. 8 Particle tracking: $V_{X}$ average velocity evolution for different jet pressures in zone 1 and in zone 2 (mass flow rate= $\left.13 \mathrm{~kg} / \mathrm{min}\right)$

For all the tested parameters, it could be observed that the mean velocity did not decrease until the end of zone 2 $\left(X_{t o t}=120\right)$. For a higher pressure of the jet $(P=3$ bars $)$, the flow stabilized only at the end of zone $1\left(X_{\text {tot }}=60\right)$. For a pressure $P=5$ bars, looking at the level and considering the standard deviations, the velocity reached its maximum only in zone 2 at a position $X_{t o t}=90$. The maximum mean velocity was $70 \mathrm{~m} / \mathrm{s}$ with some individual particles reaching $80 \mathrm{~m} / \mathrm{s}$. Since the drop of the mean velocity at the beginning of zone 2 for a pressure of 5 bars lied within the standard deviation which was important at the beginning of zone 2 $(+/-20 \mathrm{~m} / \mathrm{s})$, this drop was not analyzed in this study.

Particle tracking using FIJI software also permitted to obtain the average velocity of each detected particles over an observed zone. The frequency and the cumulative frequency normalized distributions are plotted in Fig. 10 for zone 1 and zone 2 respectively.
In zone 1 just at the nozzle exit $(0<X<60)$, for a low jet pressure $(P=1 \mathrm{bar})$, the velocity distribution was unimodal with an average velocity that decreased when the mass flow rate increased. For a pressure $P=3$ bars, the velocity distribution became bimodal. The separation of the distributions in the bimodal distribution became greater when the mass flow rate increased. At a pressure $P=5$ bars, the distribution was clearly multimodal. This multimodal effect of the frequency distribution of the average velocity of the particles was due to the potential core region where the particles had a lower velocity compared to particles that had their track in the mixing region. In zone 2 , the multimodal effect of the velocity distribution of a particle track was less pronounced than in zone 1 . It could only be observed for the greatest pressure $(P=5$ bars $)$, where the width of the distribution was increased.
Fig. 9 Evolution of the average shot velocity as a function of the position $X$ in zone 1 (a) and in zone 2 (b). Position $X=0$ in zone 2 corresponds to position $X=60$ in zone 1

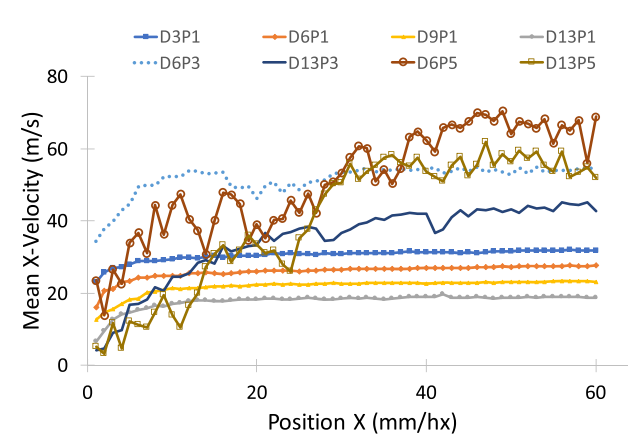

(a)

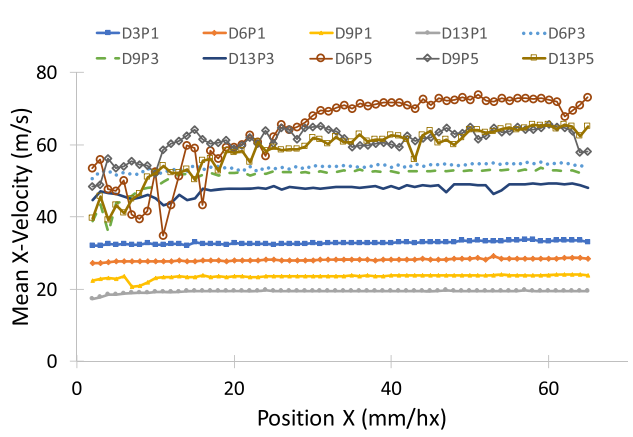

(b) 


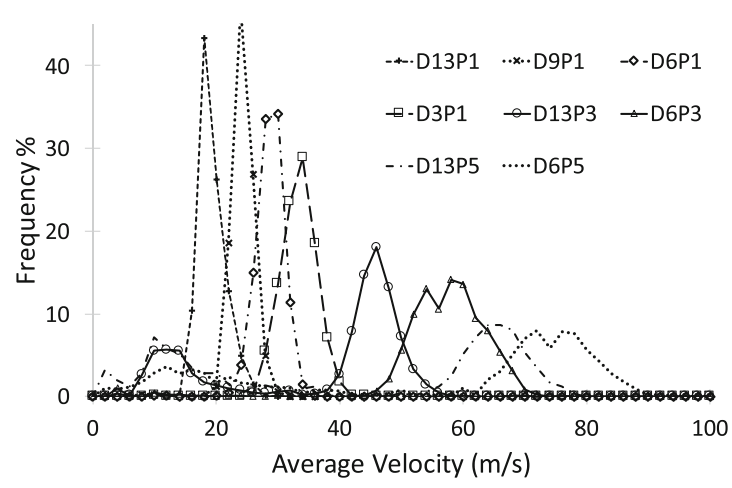

(a)

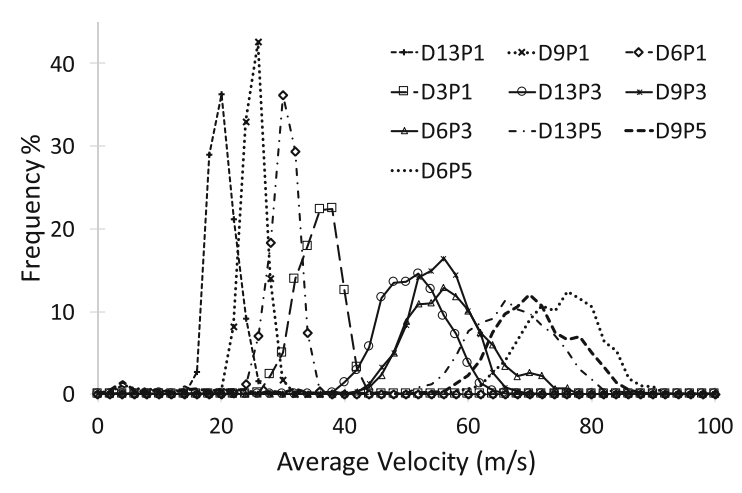

(c)

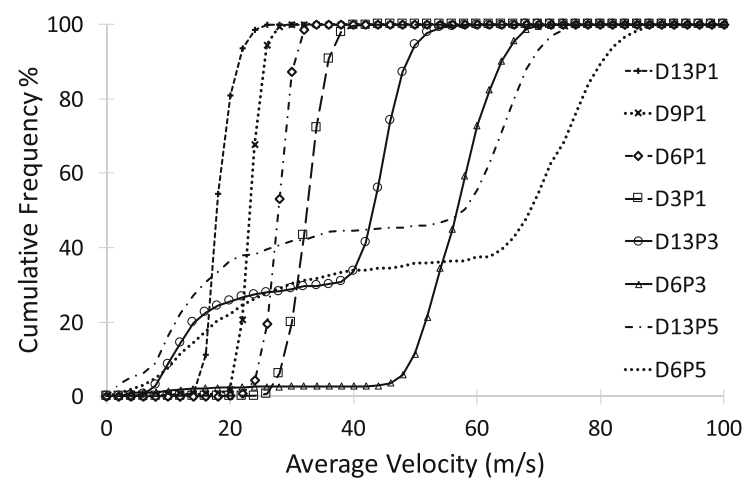

(b)

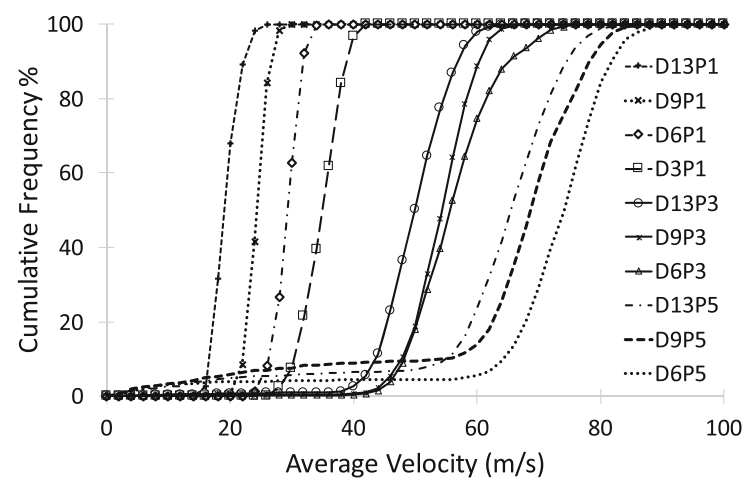

(d)

Fig. 10 Frequency and cumulative frequency distribution of the average total velocity of a particle track in (a-b) zone 1 and in (c-d) zone 2. Effect of mass flow rate and air-jet pressure. Discrete bin of $2 \mathrm{~m} / \mathrm{s}$

\section{Results: Velocity Profiles}

The velocity profiles were also analyzed in the transverse direction of the flow (direction $Y$ ). Figure 11 presents the $V_{X}$ velocity profiles as a function of $Y$ position for different distances $X$ respectively for zone 1 and zone 2 . The velocity profile was generally at its maximum at the center of the particle flow. It was observed that close to the nozzle in zone 1 , there was a velocity drop especially for high pressures (Fig. 11(a)). This drop of velocity defines the potential core region. For low velocities $V_{X}^{\max }$ under $25 \mathrm{~m} / \mathrm{s}$ (case $D 13 P 1)$, the velocity profile appeared non symmetric. The velocity was slightly higher for particles in the upper part of the flow. The $D 13 P 1$ experiment, as observed in Fig. 4, has the flow with the highest density of particles. The particle density at a given time appeared inhomogeneous in the stream, higher towards the bottom part of the nozzle exit with the particles being closer to each other. This asymmetry of local particle density, phenomenon usually called "clustering" or "preferential concentration" [33] led to a lower velocity in the bottom part of the flow. This could be caused by more frequent collisions of particles and the interactions of particles with the straight nozzle during their acceleration in the nozzle. In order to understand the "clustering" phenomenon occuring at low velocities, a more detailled fluid mechanics analysis should be performed on the air jet and in the nozzle.

\section{Results: Particle Count in Zone 1 and 2}

Particle Tracking (PT) technique enabled to obtain the position of each particle. A particle count was performed other the same 400 images used to obtain the velocity of each particle and its mean value over the particle path. Individual particles were counted over surfaces $S$ of area $4 \mathrm{~mm}^{2}$ over a duration. Individual particles were counted even if they did not belong to a path considered for velocity measurement after filtering. This led to a higher number of particles being taken into account for particle count.

Figure 12 presents the particle count contours respectively in zone 1 and zone 2 . In zone 1 , it was difficult to analyze the data for a low pressure $P=1 \mathrm{bar}$. The number of particles over a period of time was greater near the centerline, which was due to the $2 \mathrm{D}$ projection of particles of the axisymetric stream. For jet pressures of $P=3$ and 5 bars, it seemed logical that the number of particles per projected area decreases as the distance to the nozzle increases. For zone 2 and jet pressure of 3 and 5 bars, it appeared that 
Fig. $11 V_{x}$ velocity profiles as a function of position $\mathrm{Y}$ in the flow at different distances $\mathrm{X}$ from the nozzle for different process parameters in a zone 1 and $\mathbf{b}$ zone 2

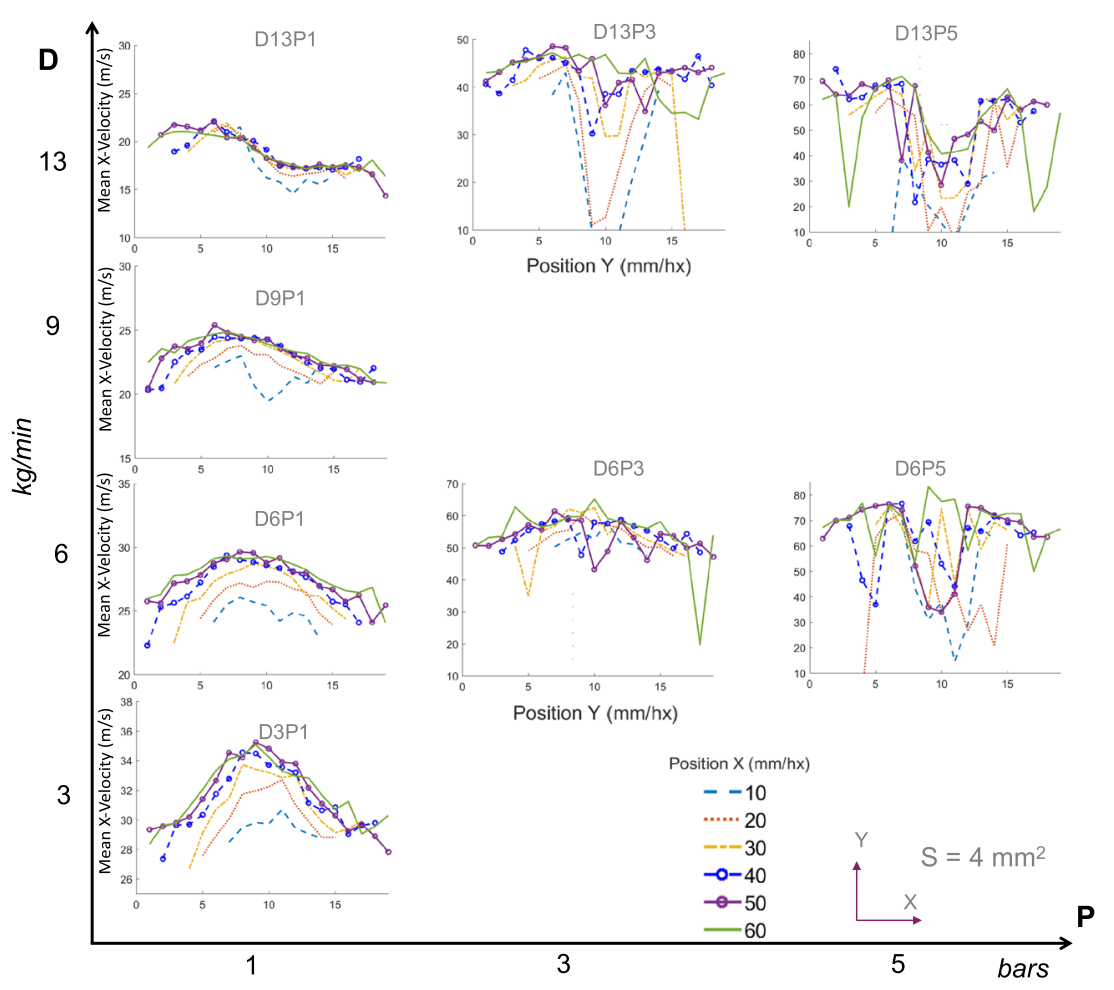

(a)

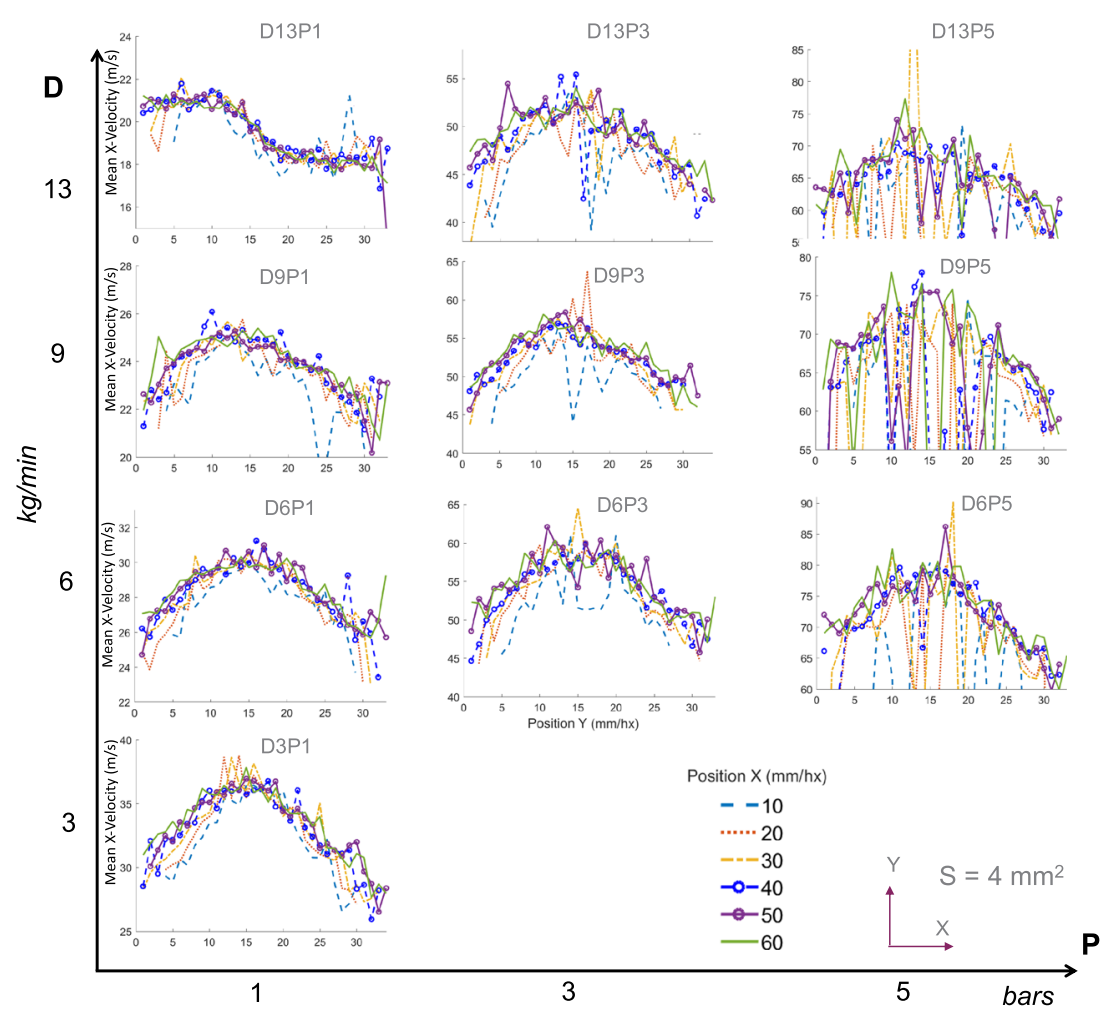

(b) fewer particles are present in the centerline of the stream. Particles were located on a ring next to the centerline of the stream. Lau and Nathan [14] suggested a process of particle reorganisation (particle size $<40 \mu \mathrm{m}$ ) selected by Stokes number, resulting in significant particle migration to the jet axis or away from the centreline respectively for low values 
Fig. 12 Particle tracking: Particle count in the flow ahead of the nozzle in a zone 1 and $\mathbf{b}$ zone 2 for different process parameters. Average over a surface $\mathrm{S}$ of $4 \mathrm{~mm}^{2}$, $h_{x}=h_{y}=2 \mathrm{~mm}$

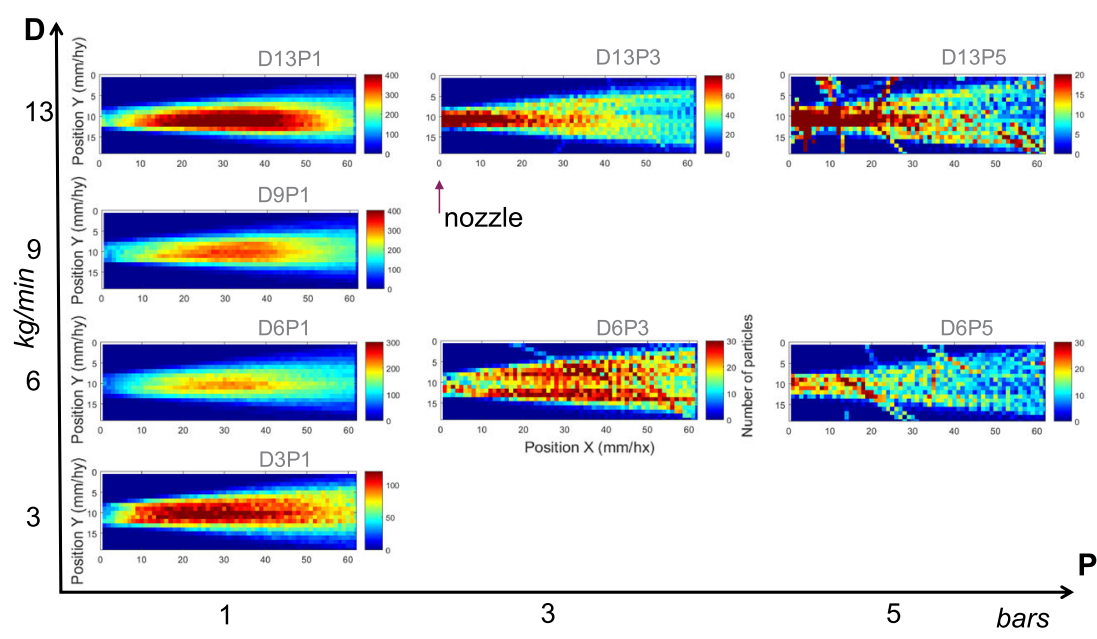

(a)

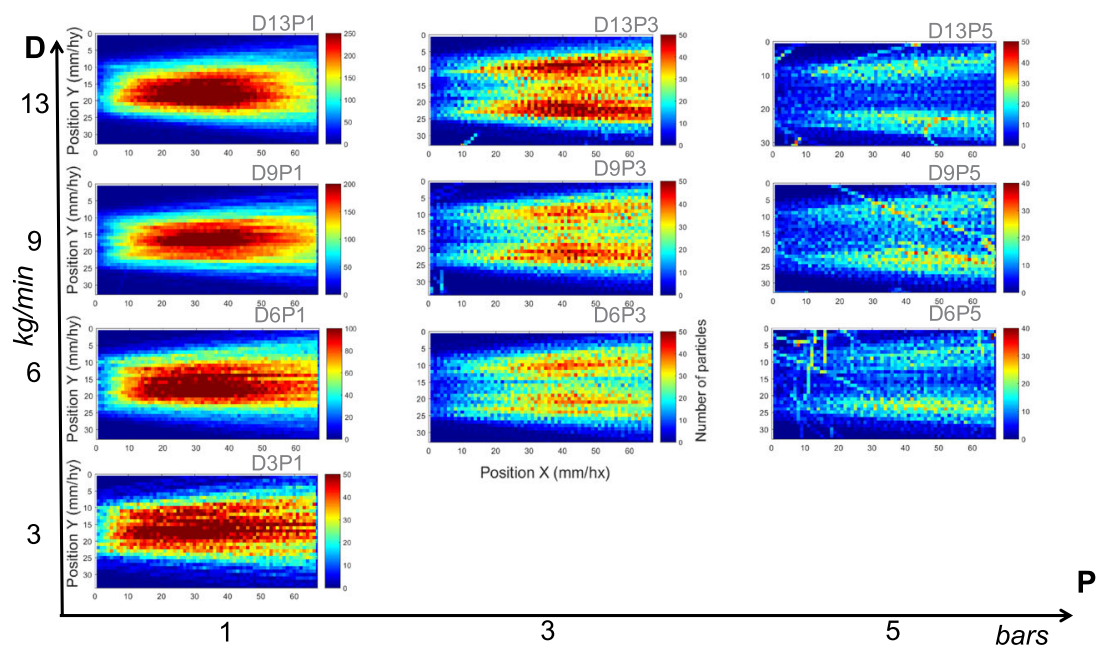

(b) of Stokes number or for high values of Stokes number. For a given particle type and size in a fluid, the Stokes number increased with the mean velocity of the gas. A more detailed fluid dynamics investigation has to be performed to analyze this effect where particles have a bigger size $(584 \mu \mathrm{m})$.

Particle tracking using 2D high speed observations was feasible and allowed a deterministic characterization of an axisymetric stream of particles outside of a nozzle by their velocity and their position for particle count. For the process parameters used, the higher the pressure, the greater the velocity $V_{X}$. The mass flow rate $D$ had an inverse effect on the velocity. Indeed, the velocity decreased as the mass flow rate increases. This was due to less force of the air pressure acting on each particle that were potentially hidden by others when the mass flow rate becomes higher. In zone 1 , at the nozzle exit, the potential core region was clearly observed by particle tracking analysis. The length of the core region increased with the pressure and with the mass flow rate. Zone 2 did not show the potential core region for any of the tested process parameters, which means that the flow was fully established. By looking at the frequency and cumulative distribution of the average velocity of particle tracks, it was observed in zone 1, that some particles remained in the potential core region and had a much lower velocity. A multimodal frequency distribution of velocities was thus observed. However, in zone 2, further away from the nozzle the multimodal distribution of velocity almost disappeared. The frequency distribution of velocities became wider as the pressure increased. The mass flow rate $D$ did not have a significant effect on the width of the frequency distribution.

To progress in the field of particle tracking applied to shot peening nozzle, 3D analysis with 2 synchronized high speed cameras or using mirrors to obtain another field of 
Table 1 DIC parameters in Ncorr with RG-DIC method

\begin{tabular}{ll}
\hline Ncorr parameters & Value \\
\hline cutoff_diffnorm & $10^{-6}$ \\
cutoff_iteration & 50 \\
total_threads & 6 \\
stepanalysis & enabled - SeedPropagation \\
subsettrunc & disabled \\
cutoff_corrcoef & 0.5 \\
lenscoef & 0 \\
\hline
\end{tabular}

view would be useful to: a) discriminate particles near the centerline of the stream from ones on the edges, b) investigate asymmetric streams.

\section{Analysis Using Digital Image Correlation (DIC)}

This section intends to present the feasability of another technique to investigate the velocity field of particles ahead of a shot peening nozzle. The obtained results were compared to the ones obtained with Particle Tracking.

\section{DIC Technique on Particles in a Flow}

Digital Image Correlation (DIC) was applied on the same sets of 2D images obtained with the high speed camera. A displacement field was calculated by comparing the obtained patterns between two subsequent images. The open source 2D DIC software Ncorr v1.2 [34] within MATLAB environment was used to calculate the displacement fields. The obtained fields were post-treated in MATLAB. Ncorr uses the reliability-guided digital image correlation (RGDIC) technique [35]. Table 1 presents the different parameters used in Ncorr. Seeds were placed regularly on the centerline of the stream, so that the region of interest was partitioned evenly.

The pattern relied on the particles with grey colors on a white background. Those particles were moving in mass inside the stream. The time between images was small enough so that the pattern could be followed between two images. Figure 13 presents the application of DIC in the stream ahead of the nozzle (zone 1). A subset radius of 39 pixels with subset spacing of 3 pixels gave the best results (Fig. 13(a)). In order to increase the accuracy, the subset spacing was less than the diameter of the particles observed in the images. The smallest subset possible was selected which does not result in too noisy displacement data. The displacement $U_{X}$ was calculated along the stream
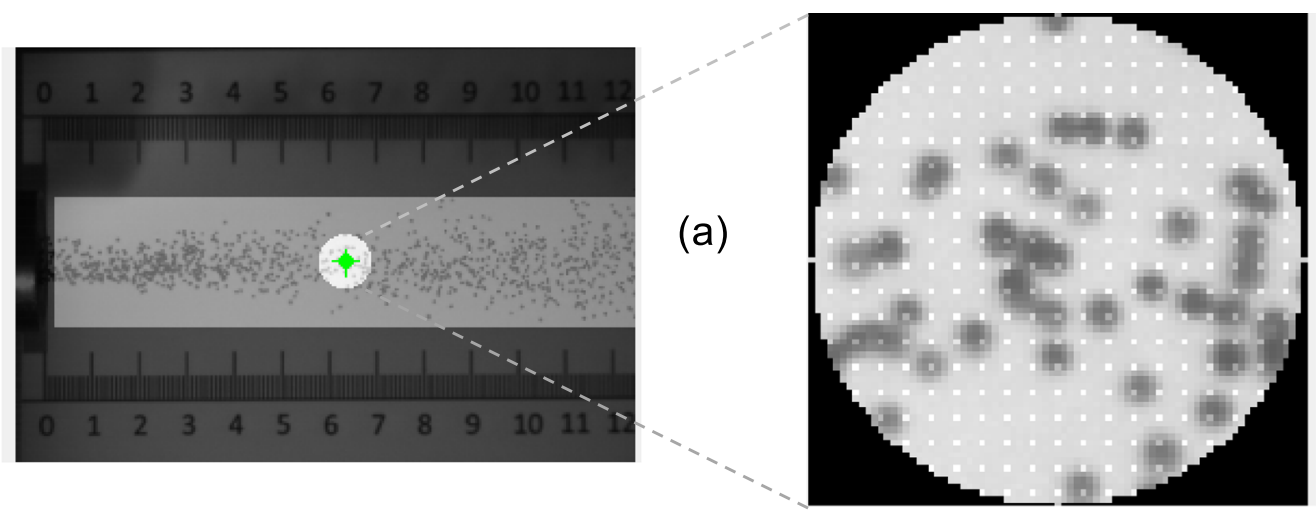

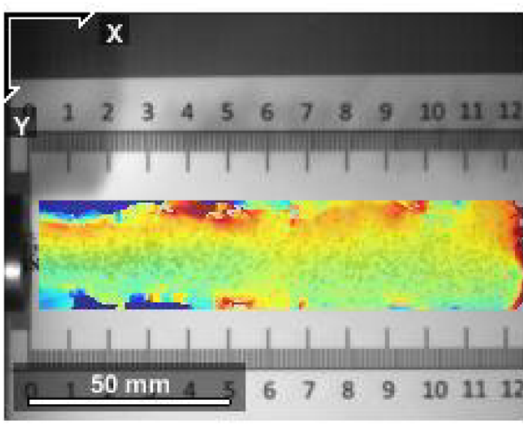

(b)

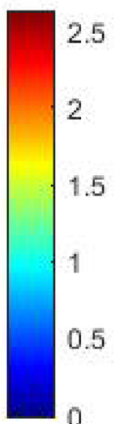

0

(a)

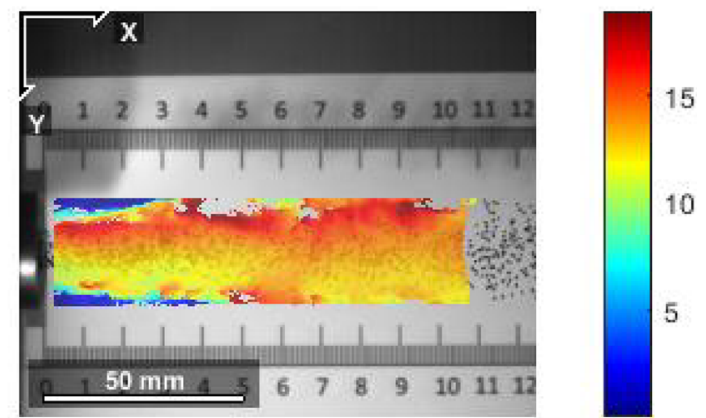

(c)

Fig. 13 DIC in the stream ahead of the nozzle in zone 1. a Subset radius 39 pixels, subset spacing 3 pixels. b Displacement field $U_{X}$ (mm) between image 1 and image 2. c Displacement field $U_{X}(\mathrm{~mm})$ between image 1 and image 9 
Fig. 14 DIC: $V_{X}$ velocity contours in the flow ahead of the nozzle in zone 1 for different process parameters. Subset radius 39 pixels, subset spacing 3 pixels. Calculation between image 1 and 2

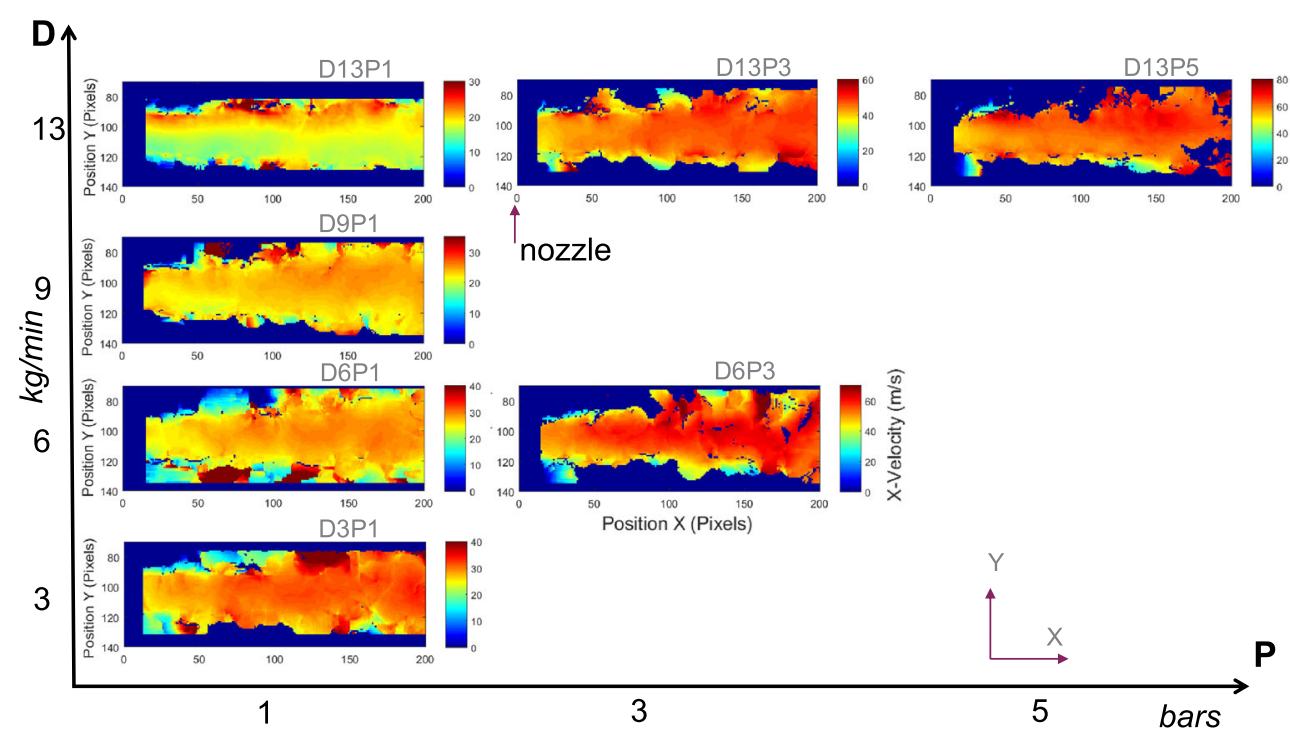

by comparing two images. Figure 13(b) and (c) presented respectively the displacement field between images 1 and 2 , and images 1 and 9. The calculated displacement was assigned at the position of the subset in the first image. It was observed that with 9 images, particles still remained in zone 1 except for particles on the far right side of zone 1. The displacement $U_{X}$ was calculated between the first 9 subsequent images.

For the process parameters tested in zone 1 (see Fig. 3), Fig. 14 presents the velocity fields between image 1 and image 2. For the process parameters (D6P5), the pattern could not be followed by the DIC software. This problem occured when the apparent density of particles linked to the mass flow rate was too low for a given velocity. The DIC results were compared to the velocity contours obtained by PT in zone 1 (Fig. 6). It was clearly observed that DIC gave less detail concerning the velocity of individual particles. Though an acceleration at the exit of the nozzle was still observed with DIC, the size of the core potential region was not as clear as for PT. For DIC, the shape of the stream was less accurate.

Figure 15 presents the case $(D 9 P 1)$ in zone 1 and zone 2. The average velocity $V_{X}$ in a section was measured versus the distance to the nozzle by using the differences of displacement for 10 subsequents images $(1-2,2-3, \ldots, 9$ 10). 9 profiles of average velocity $V_{X}$ along the stream are presented in Fig. 15. A mean value was determined over those 9 profiles.
Fig. 15 DIC: $V_{X}$ velocity contours in the flow ahead of the nozzle in zone 1 and in zone 2 for process parameters $D=9$ $\mathrm{kg} / \mathrm{min}, \mathrm{P}=1$ bar. Velocity field between two images. Average over 10 images
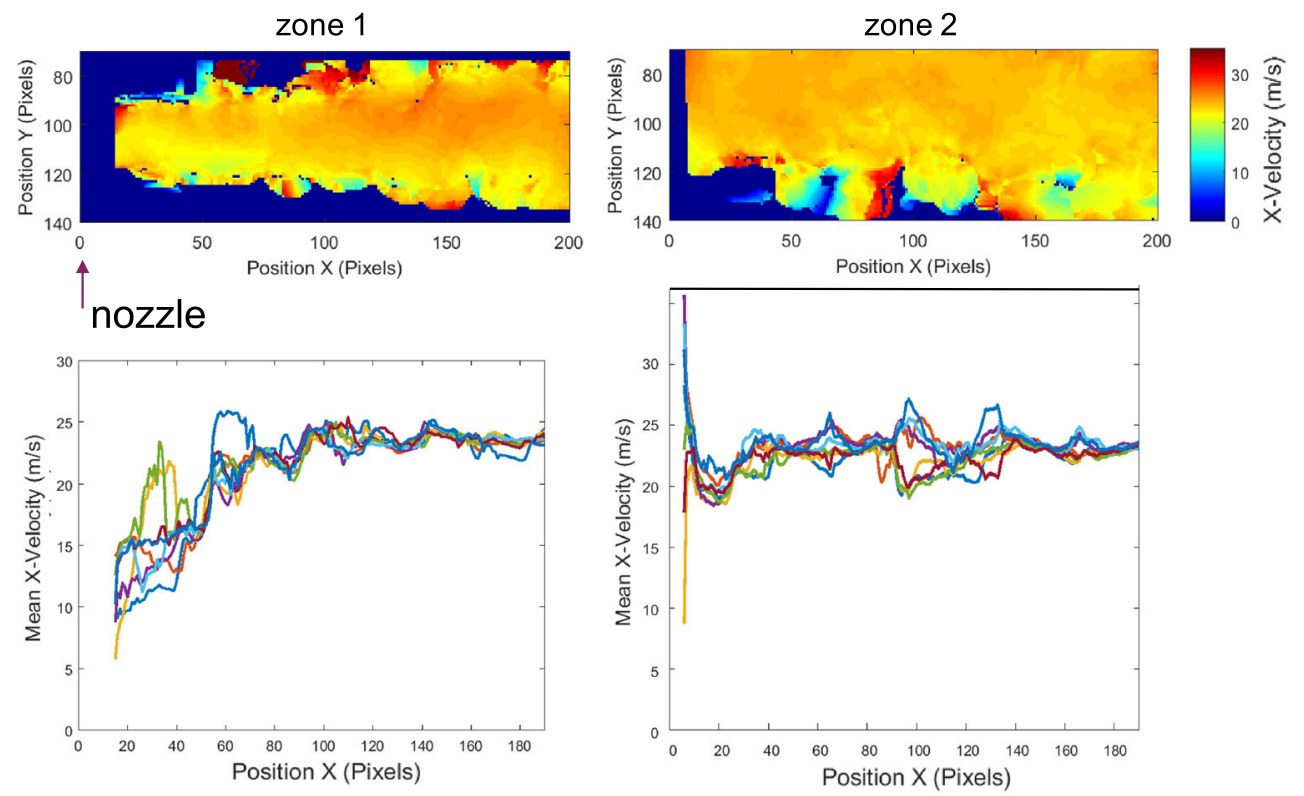


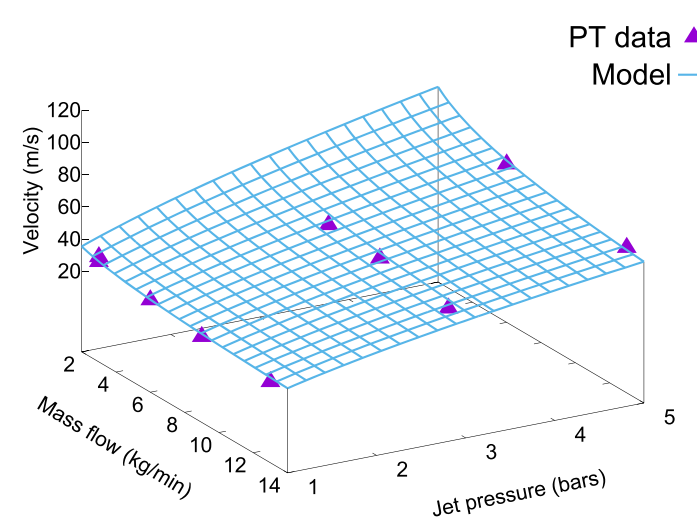

(a)

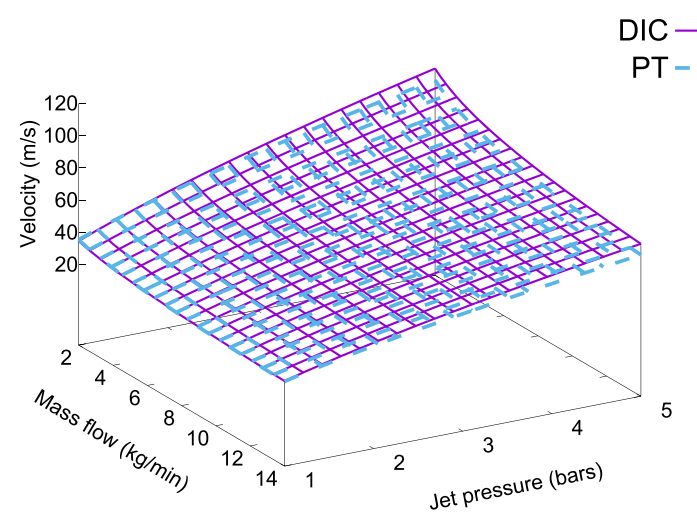

(c)

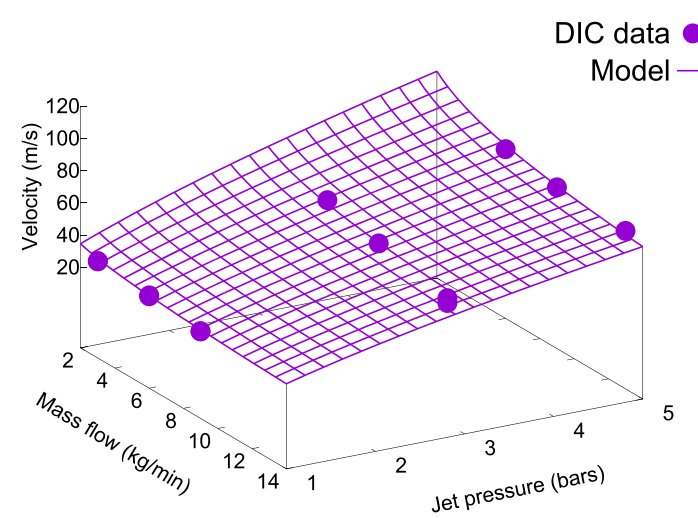

(b)

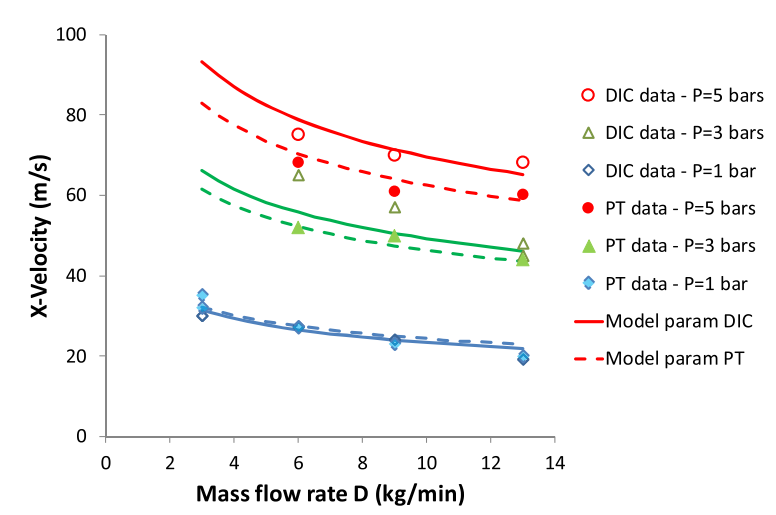

(d)

Fig. 16 Stable velocity $V_{X}^{\text {stable }}(\mathrm{m} / \mathrm{s})$ as a function of the jet pressure $P$ and the mass flow rate $D$, a PT: data vs calibrated model, $\mathbf{b}$ DIC: data vs calibrated model, $\mathbf{c}$ Comparison of the calibrated models using PT and DIC data, $\mathbf{d}$ Cut at a given jet pressure. DIC and PT data vs calibrated model

\section{Comparisons with PT and Calibration of a Phenomenological Model}

The obtained DIC data were post-treated to obtain the stabilized value of velocity $V_{X}$ for the different process parameters. A total of 18 sets of images were post-treated in zones 1 and 2.

A phenomenological model using a multiplicative power law between the mass flow rate $D(\mathrm{~kg} / \mathrm{min})$ and the air pressure $P$ (bars) was proposed to determine the maximum stable velocity of the stream $V_{X}^{\text {stable }}(\mathrm{m} / \mathrm{s})$, such as:

$V_{X}^{\text {stable }}=K \times D^{m} \times P^{n}$

where $K, m$ and $n$ are constant model parameters.

Table 2 Model parameters for PT and DIC data

\begin{tabular}{llll}
\hline & $\mathrm{K}$ & $\mathrm{m}$ & $\mathrm{n}$ \\
\hline PT & 41.7522 & -0.235109 & 0.586293 \\
DIC & 40.213 & -0.215933 & 0.648361 \\
\hline
\end{tabular}

A numerical calibration was carried out on the PT and DIC data using the fit command of Gnuplot that uses an implementation of the nonlinear least-squares (NLLS) Marquardt-Levenberg algorithm [36]. The optimized parameters using PT data and DIC data are presented in Table 2. Figure 16(a)-(c) shows the comparison between the PT and DIC data and the calibrated models. One observes that DIC data overestimate PT data for a high jet pressure $P$ of 3 and 5 bars. A cut at constant jet pressures is presented in Fig. 16(d). The average velocity $V_{X}$ drops with the mass flow rate $D$ and increases with the pressure $P$. The calibrated model gives a good fit for a low jet pressure $P=$ 1 bar, but slightly overestimates the PT data for higher jet pressures.

\section{Conclusions}

The flow of shot peening particles ahead of a straight nozzle of diameter $10 \mathrm{~mm}$ with $\mathrm{S} 230$ steel shots was characterized in $2 \mathrm{D}$, for different process parameters, using a high speed camera. The investigated process parameters were the jet 
pressure $P$ and the mass flow $D$. The velocity fields were analyzed using two techniques: Particle Tracking (PT) and Digital Image Correlation (DIC).

The conclusions of this work are:

- Using TrackMate module and Matlab, the tracks of each particle were detected for PT and a velocity field was obtained. PT enabled also particle counting to obtain an impact rate over a certain amount of time;

- DIC applied to a reduced set of images was able to capture the average displacement field of a subset of particles in motion. Measurements using DIC were feasible for almost all process parameters. For characterizing a flow of particles, the velocity field captured by DIC was less precise compared to PT but the volume of data being processed was smaller than for PT;

- The potential core region ahead of the nozzle was clearly identified with PT in zone $1(0-120 \mathrm{~mm})$. The length of the potential core region depends on the process parameters and reaches $120 \mathrm{~mm}$ for the parameters $\mathrm{D}=13 \mathrm{~kg} / \mathrm{min}, \mathrm{P}=5$ bars. This value was 12 times the diameter of the nozzle $(d=10 \mathrm{~mm})$. The potential core region can also be detected with the frequency distribution of the average velocity where a multimodal distribution appears in zone 1;

- In zone 2, far from the exit of the nozzle, the velocity profile appeared symmetric with respect to the centerline of the stream except for a low pressure or a high mass flow. The velocity was maximal on the centerline;

- DIC and PT results for axial velocity measurements were compared. Results obtained from the two techniques were in good agreement for the determination of the average stable velocity. They both predicted: a drop of the average stable velocity with the increase of the mass flow rate $D$, - an increase of the average velocity with the jet pressure;

- A phenomenological model with three parameters $(K$, $m, n)$ was used and calibrated to find a relationship between the process parameters $(D, P)$ and the axial stable velocity of the particles. The model parameters were found for PT and DIC measurements. For high jet pressure, DIC gave a higher value of velocity compared to PT.

The information about the velocity of particles and their impact rate on a structure were useful to have predictive information about the initial conditions to apply to a multiimpact Finite Element model such as developed by [37], [38] or [39]. 3D measurements using two synchronized high-speed cameras or by using a mirror from another point of view, would be a perspective to obtain the complete velocity field and to focus on the particles close to the centerline compared to the ones at the edges of the stream. Additional air velocity measurements would also be helpful to understand the fluid dynamics in interaction with particles. Numerical simulations such as Discrete Element Methods, kinematical methods or standard CFD with multiphased fluids could be compared to the experimental data of this study.

Considering the coupling with online simulations of the mechanical effects of shot peening in the material, the monitoring of the flow with such non-intrusive techniques will lead to the active control of the shot peening process.

Acknowledgments This work was conducted with the help of the French Technological Research Institute for Materials, Metallurgy and Processes (IRT M2P). The authors would like to acknowledge IRT $\mathrm{M} 2 \mathrm{P}$ and the partners of the project CONDOR led by IRT M2P.

\section{References}

1. Shakouchi $\mathrm{T}$ (2004) Jet flow engineering -fundamentals and application. Morikita

2. Kato Y, Omiya M, Hoshino H (2014) Modelling of particle behaviour in shot peening process. Journal of Mechanical Engineering and Automation 4(3):83-91

3. Tsuji Y, Morikawa Y, Tanaka T, Karimine K, Nishida S (1988) Measurement of an axisymmetric jet laden with coarse particles. Int J Multiphase Flow 14(5):565-574

4. Green RG, Gregory IA, Henry RM, Hill EJ (1986) Measurement of shot velocity at the nozzle of a shot-peening machine. In: Proceedings of 2 nd int conf on impact treatment processes, pp 221-228. cited By 5

5. Beck MS, Green RG, Plaskowski AB, Stott AL (1990) Capacitance measurement applied to a pneumatic conveyor with very low solids loading. Measurement Sci Technol 1(7):561-564. https://doi.org/10.1088\%2F0957-0233\%2F1\%2F7\%2F004

6. Ma J, Yan Y (2000) Design and evaluation of electrostatic sensors for the measurement of velocity of pneumatically conveyed solids. Flow Measurement and Instrumentation 11(3):195-204. http:// www.sciencedirect.com/science/article/pii/S0955598600000194

7. Yan Y, Byrne B, Woodhead S, Coulthard J (1995) Velocity measurement of pneumatically conveyed solids using electrodynamic sensors. Measurement Sci Technol 6(5):515-537. https://doi.org/ $10.1088 \% 2 \mathrm{~F} 0957-0233 \% 2 \mathrm{~F} 6 \% 2 \mathrm{~F} 5 \% 2 \mathrm{~F} 013$

8. Hribernik A, Bombek G, Markočič I (2003) Velocity measurements in a shotblasting machine. Flow Measurement and Instrumentation 14(6):225-231. http://www.sciencedirect.com/science/ article/pii/S0955598603000414

9. Hribernik A, Bombek G (2006) Improved method for shot particle velocity measurement within a shotblasting chamber. Flow Measurement and Instrumentation 17(2):99-105. http:// www.sciencedirect.com/science/article/pii/S0955598605000956

10. Albrecht HE, Borys M, Damaschke N, Tropea C (2003) Laser doppler and phase doppler measurement techniques. Springer, Berlin

11. Angelou N, Zhang X, Sjöholm M, Lorentzen L, Huang X (2017) Shot peening speed measurements using lidar technology. DTU Wind Energy. DTU Wind Energy E 151

12. Santo N, Portnikov D, Eshel I, Taranto R, Kalman H (2018) Experimental study on particle steady state velocity distribution in horizontal dilute phase pneumatic conveying. Chem Eng Sci 
187:354-366. http://www.sciencedirect.com/science/article/pii/ S0009250918302720

13. Aiba Y, Omiya M, Murai K, Komotori J (2014) Observation of particle behavior in fine particle peening process. In: Conf proc 2014: ICSP-12 Goslar, Germany, pp 445-449

14. Lau TCW, Nathan GJ (2016) The effect of stokes number on particle velocity and concentration distributions in a wellcharacterised, turbulent, co-flowing two-phase jet. J Fluid Mech 809:72-110

15. Prevost F, Boree J, Nuglisch HJ, Charnay G (1996) Measurements of fluid/particle correlated motion in the far field of an axisymmetric jet. Int J Multiphase Flow 22(4):685-701. http:// www.sciencedirect.com/science/article/pii/0301932296000092

16. Yilmaz A, Javed O, Shah M (2006) Object tracking: a survey. ACM Comput Surv 38(4). https://doi.org/10.1145/1177352. 1177355

17. Rosales R, Sclaroff S (1999) 3d trajectory recovery for tracking multiple objects and trajectory guided recognition of actions. In: IEEE conference on computer vision and pattern recognition (CVPR), pp 117-123

18. Meyer M, Caruso F, Lupoi R (2018) Particle velocity and dispersion of high stokes number particles by PTV measurements inside a transparent supersonic cold spray nozzle. Int J Multiphase Flow 106:296-310. http://www.sciencedirect.com/science/article/ pii/S0301932217304184

19. Amiot F, Bornert M, Doumalin P, Dupré JC, Fazzini M, Orteu JJ, Poilâne C, Robert L, Rotinat R, Toussaint E, Wattrisse B, Wienin JS (2013) Assessment of digital image correlation measurement accuracy in the ultimate error regime: Main results of a collaborative benchmark. Strain 49(6):483-496. https:// onlinelibrary.wiley.com/doi/abs/10.1111/str.12054

20. Hild F, Roux S (2006) Digital image correlation: from displacement measurement to identification of elastic properties a review. Strain 42(2):69-80. https://onlinelibrary.wiley.com/doi/ abs/10.1111/j.1475-1305.2006.00258.x

21. Sutton MA, Orteu JJ, Schreier H (2009) Image correlation for shape, motion and deformation measurements: basic concepts, theory and applications. Springer Science \& Business Media

22. Passieux J-C, Navarro P, Périé J-N, Marguet S, Ferrero J-F (2014) A digital image correlation method for tracking planar motions of rigid spheres: Application to medium velocity impacts. Experimental Mech 54(8):1453-1466. https://doi.org/10.1007/ s11340-014-9930-y

23. Horn BK, Schunck P, Brian G (1981) Determining optical flow. Artificial Intelligence 17(1):185-203. http://www.sciencedirect. com/science/article/pii/0004370281900242

24. Kuo J-C, Tung S-H, Shih M-H, Sung W-P, Kuo T-Y, Wu C-H, Hwang W-S (2014) Applying digital image correlation method to measure flow field. Int J Civil Eng 12:368-373

25. Chien C-H, Su T-H, Huang C-J, Chao Y-J, Yeh W-L, Lam P-S (2019) Application of digital image correlation (DIC) to sloshing liquids. Optics and Lasers in Engineering 115:42-52. http://www. sciencedirect.com/science/article/pii/S0143816618311874

26. Chatellier L, Jarny S, Gibouin F, David L (2013) A parametric PIV/DIC method for the measurement of free surface flows. Experiments in Fluids 54(3):1488. https://doi.org/10.1007/ s00348-013-1488-4

27. Zhao X, Sutton MA, Zhang H, Deng X, Reynolds AP, Ke X, Schreier HW (2015) Stereo image based motion measurements in fluids: experimental validation and application in friction extrusion. Experimental Mechanics 55(1):177-200. https://doi. org/10.1007/s11340-014-9907-x

28. White FM (2008) Fluid mechanics, 6th edn. McGraw-Hill, New York

29. Badreddine J, Remy S, Micoulaut M, Rouhaud E, Desfontaine V, Renaud P (2014) CAD based model of ultrasonic shot peening for complex industrial parts. Adv Eng Softw (76):31-42

30. Nguyen VB, Pohb HJ, Zhang YW (2014) Predicting shot peening coverage using multiphase computational fluid dynamics simulations. Powder Technol (256):100-112

31. Tinevez J-Y, Perry N, Schindelin J, Hoopes GM, Reynolds GD, Laplantine E, Bednarek SY, Shorte SL, Eliceiri KW (2017) TrackMate: an open and extensible platform for single-particle tracking. Methods 115:80-90. image Processing for Biologists http://www. sciencedirect.com/science/article/pii/S1046202316303346

32. Schindelin J, Arganda-Carreras I, Frise E, Kaynig V, Longair M, Pietzsch T, Preibisch S, Rueden C, Saalfeld S, Schmid B et al (2012) Fiji: an open-source platform for biological-image analysis. Nature Methods 9(7):676

33. Monchaux R, Bourgoin M, Cartellier A (2012) Analyzing preferential concentration and clustering of inertial particles in turbulence. Int $\mathrm{J}$ Multiphase Flow 40:1-18. http://www. sciencedirect.com/science/article/pii/S030193221100245X

34. Blaber J, Adair B, Antoniou A (2015) Ncorr: Open-source 2D digital image correlation matlab software. Experimental Mech 55(6):1105-1122. https://doi.org/10.1007/s11340-015-0009-1

35. Pan B (2009) Reliability-guided digital image correlation for image deformation measurement. Appl Opt 48(8):1535-1542. http://ao.osa.org/abstract.cfm?URI=ao-48-8-1535

36. Williams T, Kelley C et al (2019) Gnuplot 5.2: an interactive plotting program. http://gnuplot.sourceforge.net/

37. Gallitelli D, Boyer V, Gelineau M, Colaitis Y, Rouhaud E, Retraint D, Kubler R, Desvignes M, Barrallier L (2016) Simulation of shot peening: from process parameters to residual stress fields in a structure. Comptes Rendus Mécanique 344(4):355374. Computational simulation of manufacturing processes http:// www.sciencedirect.com/science/article/pii/S1631072116000279

38. Kubler RF, Berveiller S, Bouscaud D, Guiheux R, Patoor E, Puydt Q (2019) Shot peening of TRIP780 steel: experimental analysis and numerical simulation. J Materials Process Technol 270:182-194. http://www.sciencedirect.com/science/article/ pii/S0924013619300871

39. Boyer V (2017) Modélisation du grenaillage d'un alliage de nickel avec prise en compte de l'écrouissage et de la microstructure. Ph.D. Thesis, UT Troyes

Publisher's Note Springer Nature remains neutral with regard to jurisdictional claims in published maps and institutional affiliations. 